Chapman University

Chapman University Digital Commons

4-10-2020

\title{
Together We Can Do So Much: A Systematic Review and Conceptual Framework of Collaboration in Schools
}

Amy-Jane Griffiths

Follow this and additional works at: https://digitalcommons.chapman.edu/education_articles

Part of the Curriculum and Instruction Commons, Educational Assessment, Evaluation, and Research Commons, Educational Methods Commons, and the School Psychology Commons 


\section{Together We Can Do So Much: A Systematic Review and Conceptual Framework}

of Collaboration in Schools

\section{Comments}

This is a pre-copy-editing, author-produced PDF of an article accepted for publication in Canadian Journal of School Psychology in 2020 following peer review. The definitive publisher-authenticated version is available online at https://doi.org/10.1177/0829573520915368.

\section{Copyright}

The authors 
Running Head: REVIEW AND CONCEPTUALIZATION OF COLLABORATION

Together We Can Do So Much: A Systematic Review and Conceptual Framework of Collaboration in Schools 


\begin{abstract}
Effective collaboration is associated with positive outcomes for students and is a key component of equitable educational opportunities. There are challenges to effective collaboration, however, as our understanding of it differs based on the various definitions in the literature. The purpose of this systematic review is to identify the common constructs across definitions of collaboration as a means to develop a universal model that can be used in the schools. Through the development of a "building blocks" framework, we provide a common definition and identify the steps that must be taken before true collaboration can occur. This model highlights the iterative nature of the collaborative process and the importance of revisiting the foundational aspects of collaborative development. The systematic review focuses on using a common definition for research and the practice of collaboration.
\end{abstract}

Keywords: multidisciplinary, collaboration model, partnerships, family-school, consultation 
Children enter school with a variety of strengths and struggles across multiple domains of their lives. Providing comprehensive education and support for all children, including those with disabilities, is a critical and challenging issue that can be solved if all individuals work together. A common goal of the education system is to provide high-quality education for all children, creating the need for effective collaboration. In fact, this collaborative work between individuals in the educational setting is required by law for students with disabilities through the Individuals with Disabilities Education Improvement Act (IDEIA; 2006). Under IDEIA, Individual Educational Program (IEP) members, including educators and parents, are required to contribute to the collaborative process, which is designed to ensure that individuals with experience working with the child, regardless of context or professional background, are involved in the creation of a comprehensive and integrated intervention program. This relationship between school team members provides the foundation for the student's educational program and longterm outcomes. Further, the quality of this relationship is a determining factor for the effectiveness of a student's IEP (Reiman, Beck, Coppola, \& Engiles, 2010).

As seen in the literature, collaboration is a well-established practice. Although collaboration varies, depending on the setting, there is a consensus that collaboration leads to more effective communication (Cowan, Swearer, \& Sheridan, 2004), stronger and more sustainable relationships (Peterson, 1991), reduced stress among stakeholders (Brookman-Frazee \& Koegel, 2004), and the attainment of goals that would otherwise not be possible (Wood \& Gray, 1991). In the school setting, students experience better academic, social-emotional, and behavioral outcomes when schools, communities, outside agencies, and families work together (Henderson \& Mapp, 2002). 
Specifically, research indicates positive relationships and collaboration between schools and families can lead to positive learning outcomes for students (Carlson \& Christenson, 2005; Epstein, 2001; National Association of School Psychologists, 2012), including higher achievement in reading (Esler, Godber, \& Christenson, 2008) and increased interest in literacy (Cox, 2005). In addition, collaboration in the school setting is associated with higher quality and increased completion of classwork and homework (Cox, 2005; Esler et al., 2008) as well as overall attitudes toward school (Esler et al., 2008). Collaboration between schools and families can help decrease both internalizing and externalizing problem behaviors (Blair, Lee, Cho, \& Dunlap, 2011; Cox, 2005) and influences a child's social competence and relationship with their teacher (Serpell \& Mashburn, 2011).

For teams, collaboration allows for the interchange of ideas and strategies among individuals with differing experiences, knowledge, and skill. These various ideas allow for teams to achieve goals that they may not otherwise attain on their own (Gajda, 2004; Wood \& Gray, 1991). In the school setting, collaboration allows educators and parents to understand children across a variety of settings, as well as to communicate differences and avoid unnecessary tension and conflict (Cowan et al., 2004). This should result in parents and staff's working more effectively in creating and implementing student support plans.

However, the complexity of school systems makes it particularly difficult for school professionals to solve problems independently. Rather, they must use a team perspective to enhance outcomes for students. It is common practice for teams of both overlapping and unique members to form in order to address student and systemic needs (e.g., Individual Education Plan Teams, Student Study Teams, Multi-tiered Student Support Teams). Further, across the various teams, there may be different trainings, concepts, and theoretical foundations in regard to 
working together that underlie each teams' approach. These potentially inconsistent messages may be confusing to team members. These messages could result in impaired communication, misunderstandings regarding roles and responsibilities among members, and thus inconsistent results for student success. Thus, finding a way to create a consistent and successful collaborative practice within the educational team context is needed.

When families and school teams build positive relationships and communicate effectively, the process becomes more collaborative. As a result of this collaboration, children experience better academic outcomes, including higher academic achievement, higher quality of work, and higher rates of work completion (Carlson \& Christenson, 2005; Cox, 2005; Epstein, 2001; National Association of School Psychologists, 2012). Nevertheless, there are challenges in these types of educational teams, and districts have continued to struggle with creating consistent, collaborative, and successful partnerships with families (Tucker \& Schwartz, 2013).

\section{Confusion and Lack of Agreement about Terms}

Despite the vast amount of research on the importance of collaboration, a number of proposed collaboration models, and associated positive outcomes in the fields of education, business, and healthcare and in the community, there is not a comprehensive and empirically supported model of collaboration in the educational literature. Collaboration is frequently used as a broad term that is associated with an assortment of constructs in regard to team member interactions across various settings. The definitions and use of terms tend to overlap and sometimes appear to be used interchangeably (e.g., collaboration, family-school partnership, strategic alliance), making it difficult to clearly define collaboration and its associated outcomes (Gajda, 2004). 
This lack of agreement and the use of broad, relatively undefined terms, has spurred a number of studies that evaluate the elements of collaboration, but no study has measured exactly the same variables or constructs. Many of these studies focus on select elements of collaboration identified in the literature, including communication (e.g., Abramson \& Mizrahi, 1996; Adams \& Christenson, 2000) trust (e.g., Adams \& Christenson, 2000; Amabile et al., 2001; Blue-Banning et al., 2004; Williamson et al., 2016), and shared responsibility (e.g., National Association of School Psychologists, 2012; Olivos et al., 2010; Olson, 2003; Tucker \& Schwartz, 2013), but do not consider all of the common components across the literature base. Therefore, an in-depth look at what characterizes "true collaboration" is lacking in the current literature, and guidance for developing such collaborative relationships is scarce. Without a strong foundational definition, the field will not be able to compare results across studies or settings or have the ability to advance the field in terms of best practices.

To address this need, we conducted a systematic review of the collaboration literature, with the goals of identifying salient elements of collaboration in the present literature and developing a "building blocks" model of collaboration. This model includes the foundation for developing a collaborative relationship and the specific elements that help the team to truly collaborate throughout the process. By explicitly defining the constructs that comprise successful team collaboration, researchers and practitioners will be able to more effectively measure these concepts in practice. We can also provide more specific guidelines for implementation, enhance the quality of collaboration across team members, and, ultimately, improve outcomes for students.

\section{Method}


A search of theoretical and empirical collaborative models, constructs, and measures was conducted using the online databases PsycINFO, PubMed, JSTOR, Academic Search Premier, and ProQuest. Using the keywords "collaboration," "family-school partnership," "strategic alliance," "communication," "school-based teams," "interdisciplinary team work," and "homeschool relationships." Researchers reviewed the existing literature on collaboration published between 1992 and 2017. The research team decided on a 25-year timeframe due to trends in the literature, in which many seminal articles were released in the early 1990 s and were considered essential in the review. Reference lists from articles that met the initial search criteria were also reviewed to identify additional articles that may not have appeared in the initial search. During the screening process, two independent reviewers screened titles, abstracts, and full texts for eligibility. Reviewers deposited relevant articles in a shared drive and duplicates were erased. The reviewers independently checked every article to ensure they met inclusion criteria. The pair of reviewers then divided the articles by article type (i.e., empirical, theoretical).

\section{Inclusion Criteria}

To be included, papers had to be published in a peer-reviewed, academic scholarly journal or academic book. Papers also had to present a theoretical or empirical model of collaboration. To expand our inclusion criteria, we included articles that presented several constructs or measures of collaboration, without proposing a definition or model of collaboration. Studies had to be conducted within the healthcare, community, or education setting. Although there are important differences between these settings, the review of the literature indicated that many of the same components were being used, regardless of the field. To develop a comprehensive model that took all of these elements into account, we included all three settings in this review. A 25-year timeframe (1992 to 2017) was used as a means to include 
seminal work in the field of collaboration that appeared in the early 1990s. Papers that aimed to further the discussion of collaboration or that applied models of collaboration without first presenting a model of collaboration or its constructs were not included.

\section{Data Extraction}

Data were extracted and tabulated from the included papers. These included sample size, setting/subjects, methods, objective, and results. Potential key constructs were highlighted and summarized for each paper in order to assist with analysis.

\section{Analysis plan}

Once included studies were selected, entered in the table, and verified by each reviewer, data were analyzed for common constructs. The included papers covered varying concepts related to collaboration and were methodologically heterogeneous. Data were therefore analyzed using a narrative approach. The reviewers independently identified themes from each eligible paper using a standardized table with detailed instructions. Studies were coded, summarized, and categorized by construct. Reviewers then compared tables and notes, resolved disagreement through discussion or, if required, adjudication by a third reviewer. Finally, a table was created with the common constructs and a summary definition of that construct. Each paper was again reviewed by the two independent reviewers to determine if the construct was present or assumed in the paper. This data was individually tabulated by each reviewer, reviewers compared results, resolved disagreement and created a final table of the results for both empirical and theoretical papers (discussed in results section below),

\section{Results}

The search of electronic databases yielded 21,438 published articles (Figure 1). Of those, 135 articles met the preliminary inclusion criteria (described above), and an additional 12 were 
found through reference checking. After full article review, 15 articles met the criteria for presenting a model of collaboration, and 19 articles provided information regarding the salient elements and/or constructs of collaboration. After full article review and exclusion of articles that did not meet criteria, we analyzed a total of 34 articles.

[Insert Figure 1 about here]

Although many of the papers differed in their definition and identified key constructs of collaboration, there were similar elements among many of the articles (Table 1). Further, although different terms were used interchangeably to describe a specific type of collaborative relationship, many of the definitions included similar components. Through an in-depth review and analysis, described above, each member of the research team reviewed the articles and coded and organized similar terms (e.g., "communication" and "open communication," "shared vision" and "common understanding"). The team members than reviewed their individual codes, combined those with similar meaning, and extracted themes in an effort to identify key constructs. The team identified eight key common constructs that led to collaboration: (a) open communication, (b) trust, (c) mutual respect, (d) shared goals, (e) common understanding, (f) shared responsibility, $(\mathrm{g})$ active participation, and $(\mathrm{h})$ shared decision making.

[Insert Table 1 about here]

Table 2 provides a summary of the constructs that includes the eight constructs, key points, and references that pertain to each construct. Differences in language (e.g., "shared vision" versus "common understanding") were noted within the key points to show the similarities between terms used in different articles. In addition, Tables 3 and 4 provide a summary of the common elements between empirical and theoretical definitions, respectively. 
The purpose of these tables is to show that, although many current models in the literature touch on similar constructs, no model explicitly includes all eight constructs identified in this paper.

[Insert Tables 2-4 here]

Based on this review, collaboration can be defined as a complex process built on trust, open communication, and mutual respect (relationship building), with all members focused on shared goals and responsibility with a common understanding (shared values), who are actively participating with a sense of shared responsibility (active engagement) and decision making. We also included a ninth element, implementation, although this was not explicitly listed in any of the articles that we reviewed. Nevertheless, it is clear that, without implementation, collaborative team experiences are not effective. Shared decision making and implementation thus combine to create the overall collective collaborative effort. This definition and elements identified in our review led to the development of a "building blocks" conceptual model of collaboration, as discussed below.

\section{Conceptual Model (Based on Analysis)}

Based on our a systematic review of articles that pertain to collaboration, we provide a comprehensive definition and model that explain how these elements interact to guide effective collaboration. We also incorporate elements not frequently included in the current body of literature (e.g., implementation). It is important to note that, although discussions of collaboration may include personal characteristics (e.g., an openness to new ideas), we believe that, in a model of collaboration, the key elements are the building blocks of collaborative teams and how the individuals in these teams can enhance these personal characteristics for the good of the team. When considering who should be a member of the team, one should think about all who are involved with students, both within and outside of the school system. For example, team 
members may include parents, students, school professionals (e.g., teachers, administrators, school psychologists, school counselors, instructional staff), and outside providers.

Our "building blocks" model is presented in Figure 2. This model addresses the notion that collaboration development is a dynamic process across multiple systems (e.g., families, schools, community providers), utilizing collaboration models from various interdisciplinary sectors (e.g., school, business, and healthcare). The model emphasizes the importance of collaboration through an interactive and deliberate process across all stages of relationship development. These processes of pooling resources are considered to be core elements of student-centered support and foundational for the creation of collaborative teams/relationships (Chong, Aslani, \& Chen, 2013; Cowan, Swearer, \& Sheridan, 2004).

[Insert Figure 2 about here]

The model is displayed as a set of "building blocks" to emphasize the requirement that the initial building blocks are developed and cultivated before additional ones can be added. As the collaborative team builds on their foundation and progresses through the blocks, it is important that they continue to address the foundational skills developed below. The arrows indicate that this is an iterative process and that teams will continue to cycle through these various stages, sometimes having to repair components of the collaborative relationship before moving forward in the process. Team members will need to continually solicit feedback and use it as a part of the loop of information. The processes of and terms related to the model are presented below.

Relationship Building . A number of concepts presented in the articles reviewed concerned the importance of effective relationships. Before a team can begin to meaningfully engage in the process and make shared decisions, a strong foundation among team members 
must be developed. Relationship building includes the establishment of open communication, trust, and mutual respect. Open communication occurs when all parties are able to comfortably express ideas with one another in an effective manner. Effective communication typically occurs when communication is open, honest, and clear, which allows each member the opportunity to share his or her ideas and helps avoid unnecessary conflict (Lancaster, Kolakowsky-Hayner, Kovacich, \& Greer-Williams, 2015). It is important the team is able to communicate about the process and changes that may be required, and, as such, flexibility and adaptability are important characteristics of the collaborative team (Bronstein, 2003).

Lines of communication can be both formal and informal (Hallam, Smith, Hite, Hite, \& Wilcox, 2015). Further, all members of the team need to have access to all information such that there is no denial of any member's ability to contribute (Tucker \& Schwartz, 2013). Therefore, it is important to establish communication and problem-solving strategies early (Amabile et al., 2001). When goals and ideas are understood by all team members, any potential confusion or conflict are discussed openly and productively (Tucker \& Schwartz, 2013). In addition, acceptance of and openness to members' various cultures, backgrounds, experience, and knowledge are crucial throughout the collaborative process (Fewster-Thuente, 2015; Verdon, Wong, \& McLeod, 2016).

Open communication and trust are interrelated concepts that build on each other. Trust is developed only when time, effort, and energy are put into the development of an accessible and functioning system of communication (Gajda, 2004). When trust is established, members are more likely to engage in higher levels of vulnerability and open communication (TschannenMoran, 2001). Trust is defined as a willingness to make oneself vulnerable to someone else in the belief that one's interests will not be negatively affected (Tschannen-Moran \& Gareis, 2015). 
Although, at times, we think of trust in a static sense (e.g., "We have established trust"), it is something that not only takes time to develop but also needs to be fostered over time (Hodges, Hernandez, \& Nesman, 2003). Throughout the collaborative process, trust is maintained when there is a belief that everyone is working together for the common goal of the group; the group members' behaviors are predictable, reliable, and consistent; and knowledge and ideas are shared without fear of judgment in a way that fosters creative thinking, innovation, and risk taking (Hallam et al., 2015; Kellerman, 2004). The demonstration of high levels of trust and commitment by team results not only in student success but in school success (Olson, 2003).

The third aspect of relationship building is mutual respect. Trust and open communication are necessary in the process of understanding another individual's level of competence, skills, and knowledge; and mutual respect is often considered in association with trust and open communication (Pullon, 2008). Mutual respect occurs when people value each other's skills, knowledge, and competence (Adams \& Christenson, 2000; Hallam et al., 2015; Fewster-Thuente, 2015). Mutual respect is developed when ideas and knowledge are valued, there is confidence in each other's abilities and flexibility to resolve conflict constructively (Tucker \& Schwartz, 2013). Of further importance, team members should strive toward cultural understanding as well as proactively address differences in perceived power (Verdon et al., 2016).

Although individuals are trusted to follow through without micromanaging and in the absence of a power hierarchy (Hallam et al., 2015; Fewster-Thuente, 2015; Lancaster et al., 2015), conflict is inevitable. Through the development of relationships via open communication, trust, and mutual respect, conflict can be resolved in a productive fashion. In fact, the successful resolution of conflict is expected to allow participants to further enhance their relationships as a 
result of mutual respect (despite differing opinions, the relationship holds), trust (the security that one is still respected despite disagreement), and open communication (as testing the waters with lesser arguments early may allow more challenging aspects to be discussed openly later).

Successful conflict management is a crucial aspect of effective collaboration. It is crucial that teams are continually checking in to ensure these qualities endure throughout the collaborative efforts.

Shared Values and Beliefs. When a team has begun the process of developing a strong relationship, it can then identify and use areas of expertise to mutually determine a set of shared goals and objectives (Cowan, Swearer Napolitano, \& Sheridan, 2004). At the core of collaboration is a shared goal or a common problem that brings the team together to complete a task that cannot otherwise be accomplished independently (Fewster-Thuente, 2015; Olson, 2003). To develop shared goals, each member of the team provides input, and goals are mutually created and agreed upon. Interdependence is established when individuals' expertise is capitalized on and the overall tasks of the team cannot be completed without everyone working together (Bronstein, 2003). It is essential that all members feel equally able to contribute toward the common goals of the collaborative team (Hallam et al., 2015).

Along with shared goals, there also must be a common understanding among all members that, despite differences in experience, knowledge, and skill, will help them to accomplish their shared goals. As collaborative teams can be diverse in terms of members' experiences, culture, and expertise, part of the foundational process is establishing each member's role and contribution (Hodges et al., 2003). Developing continuity in collaborative relationships depends not only on consistent goals but also on common messages and understanding among team members (Glueck \& Reschly, 2014). The team must consistently attempt to establish a common 
understanding by developing shared goals, as it is at the forefront of collaboration (Adams \& Christenson, 2000; Amabile et al., 2001; Tucker \& Schwartz, 2013).

Active Engagement. Trust, open communication, and mutual respect allow for the recognition of skills, knowledge, and competence. Once a team recognizes these traits in each individual and begins to develop shared goals and a common understanding, the members can work toward active engagement via shared responsibility and active participation (National Association of School Psychologists, 2012).

Shared responsibility is the idea that each member of the collaborative team contributes his or her own expertise and that each member will have a unique role in determining potential solutions. It involves a sense of collective ownership for the outcome and a clear sense of personal roles and responsibilities for each member and across members (Hallam et al., 2015; Tucker \& Schwartz, 2013). Together, those involved in a collaboration team pool their resources to create a cooperative independent relationship (Cowan et al., 2004). At times, a team might have a reluctant member (e.g., a student who does not want to be part of special education, a staff member "forced" to sit on a committee), and, in these situations, open communication must be established. This will allow all members to share their concerns and work toward including all members in the development of the shared goal.

Directly related to the concept of shared responsibility is active participation. Active participation takes shared responsibility a step further, as each member of the collaborative team takes an active and directive role to contribute meaningfully (Cowan et al., 2004). Whereas shared responsibility includes the development of each individual's specific role, active participation requires that all team members embrace their specific role and contribute resources. 
For a team to move on to the next stage of collaboration, it is essential that all members are engaged in the work of the team and share their ideas and resources.

Collective Collaborative Effort. Once the steps in the process are undertaken, a strong foundation for collaboration is present. The final step and ultimate goal of the collaborative process is to determine solutions and implement them. As such, the final stage of collaboration includes shared decision making and the effective implementation of these decisions.

Shared decision making occurs when the team systematically gathers input from all team members by encouraging participation throughout the decision-making process. As a result of shared responsibility and active participation among team members who have developed a strong relationship, there will likely be more ideas than can be implemented (Hallam et al., 2015). Therefore, the team must establish and follow a clear procedure for making final decisions and implementing. Shared decision making demonstrated much variation in the articles that we reviewed. It was included in only one of the seven empirical articles but appeared in four of the five theoretical articles. This may indicate that it is philosophically viewed as an element of collaboration but difficult to study.

Effective implementation is the final and perhaps most important aspect of the collaborative process. Implementation is defined by the team enacting the decisions that are made, ensuring fidelity (Dulaney, 2012). Although a crucial aspect of the team process, this concept in collaboration often did not appear in the literature. In fact, although briefly mentioned a few times, it was not a focus of any of the articles that we reviewed. If the team is able to effectively collaborate and develop a strong plan for the student, but is not able to successfully implement the plan, the outcome for the student will not change. Therefore, the final aspect of the collaborative planning process should be to create and apply short and long term 
implementation activities (Fixsen 2005, Hall \& Hord2020) that will facilitate the success of the plan developed for the student's real world context. Given the focus on shared implementation across team members, school psychologists may use coaching practices to build the skills of the other team members and facilitate enhanced implementation outcomes (Freeman, Sugai, Simonsen, \& Everett, 2017; Sanetti \& Collier-Meek, 2019)

One key role in the implementation of a collaborative team's efforts is the role of facilitator. A school psychologist, for example, may be the facilitator in an IEP team. The facilitator will assist in monitoring the collaborative process and how the team is progressing through the steps as well as keeping the team on the path to effective implementation. Accountability and follow-through can be monitored through treatment integrity checks and continuous progress monitoring of the interventions identified (Bickman et al., 2009).

Collaboration among all stakeholders in a child's education is an essential component of ensuring a comprehensive and integrated intervention program. When all members of the collaborative process have developed a working relationship and common understanding, teams can develop and implement appropriate programs for children. The collaboration between schools, outside agencies, and families can lead to many benefits for everyone involved. Efforts among school psychologists, school counselors, and teachers, for instance, to work together may increase the overall effectiveness of a child's IEP (Rowley, 2000). We must also consider that as with any systemic change in a school system, these processes take time to develop and become a part of the school culture. Although it is not clear how long it may take to build consistently collaborative teams, it will likely take an organized effort to build and sustain this process in a school. 
In order to help facilitate this collaborative problem solving process we created a questionnaire (Patten, 2014) to help in the development of collaborative teams (Figure 3). This instrument is designed as a criterion referenced list of attributes that are necessary in order to build a collaborative culture in a team. Each team member may respond anonymously to the questions in the checklist, and then the team leader or the team as a group should review the results and address areas of need.

[Insert Figure 3 about here]

\section{Conclusion and Future Directions}

Through our systematic review, we have illuminated some of the underlying elements of collaboration, specifically within the context of education. This review provided a preliminary look at how collaboration is defined across the literature and how it can be operationalized so that future research and practice can be enhanced. The limited number of empirical studies available in regard to collaboration (that met our criteria) calls for a cautious interpretation of our results.

Despite these limitations, we feel that, by providing a more comprehensive working definition of collaboration and its most salient elements, our findings will facilitate future research into collaboration and help to improve collaboration in education. We recommend further investigation into the effective measurement of the identified collaborative elements in school problem-solving teams. It will be important to evaluate how these elements interact with one another and collaboration as a whole and how they are related to team and individual student outcomes.

Relevance to the Practice of School Psychology. As mandated by IDEIA, school psychologists and other educators must build collaborative relationships with parents in order to 
improve student outcomes (IDEIA, 2006; Reiman, Beck, Coppola, \& Engiles, 2010). The evidence is clear - children experience improved outcomes when parents and schools collaborate effectively (Carlson \& Christenson, 2005; Cox, 2005; Epstein, 2001; National Association of School Psychologists, 2012); how we go about doing this is not as clear. Considering the positive outcomes of effective collaboration and the knowledge base of the school psychologist, it is recommended that they take a leadership role in establishing effective collaboration in their schools. The school psychologist may act as the facilitator and ensure the team follows each of the building blocks in the collaboration model, help team members process difficulties along the way, and provide feedback when possible. Collaboration, as noted in the National Association of School Psychologists Practice Model (2010), is critical for school psychologists to integrate to best meet the needs of students, families, and schools (Skalski et al., 2015). School psychologists and their school-based teams must systematically build positive and collaborative relationships with each other, and with the families and children they serve. 


\section{References}

Abramson, J. S., \& Mizrahi, T. (1996). When social workers and physicians collaboration: Positive and negative interdisciplinary experiences. Social Work, 41, 270-281.

Adams, K. S., \& Christenson, S. L. (2000). Trust and the family-school relationship examination of parent-teacher differences in elementary and secondary grades. Journal of School Psychology, 38, 477-497.

Amabile, T. M., Patterson, C., Mueller, J., Wojcik, T., Odomirok, P. W., Marsh, M., Kramer, S. J. (2001). Academic-practitioner collaboration in management research: A case of crossprofessional collaboration. Academy of Management Journal, 44, 418-431.

Bailey, D., \& Koney, K. (2000). Strategic alliances among health and human services organizations: From affiliations to consolidations (Abr. ed.). Thousand Oaks, CA: Sage.

Beverly, C. L., \& Thomas, S. B. (1999). Family assessment and collaboration building: Conjoined processes. International Journal of Disability, Development and Education, 46, 179-197.

Bickman, L., Brown, J. L., Flay, B. R., Li, K. K., Pelham Jr., W., Massetti, G., .. DuBois, D. (2009). Approaches to measuring implementation fidelity in school-based program evaluation. Journal of Research in Character Education, 7(2), 75-101.

Blair, K. S., Lee, I. S., Cho, S. J., \& Dunlap, G. (2011). Positive behavior support through family-school collaboration for young children with autism. Topics in Early Childhood Special Education, 31, 22-36. 
Blue-Banning, M., Summers, J. A., Frankland, H. G., Nelson, L. L., \& Beegle, G. (2004). Dimensions of family and professional partnerships: Constructive guidelines for collaboration. Exceptional Children, 70, 167-184.

Boyer, V. E., \& Thompson, S. D. (2014). Transdisciplinary model and early intervention: Building collaborative relationships. Young Exceptional Children, 17(3), 19-32.

Bronstein, L. R. (2003). A model for interdisciplinary collaboration. Social Work, 48, 297-306.

Brookman-Frazee, L., \& Koegel, R. L. (2004). Using parent/clinician partnerships in parent education programs for children with autism. Journal of Positive Behavior Interventions, 6, 195-213. doi: 10.1177/10983007040060040201

Carlson, C., \& Christenson, S. L. (2005). Evidence-based parent and family interventions in school psychology: Overview and procedures. School Psychology Quarterly, 20(4), 345351.

Center for Appropriate Dispute Resolution in Special Education (2010). Parents' experiences with the IEP process: Considerations for improving practice. Eugene, OR.

Cowan, R. J., Swearer Napolitano, S. M., \& Sheridan, S. M. (2004). Home-school collaboration. Encyclopedia of Applied Psychology, 2, 201-208.

Cox, D. D. (2005). Evidence-based interventions using home-school collaboration. School Psychology Quarterly, 20, 473-497.

Dinnebeil, L. A., Hale, L. M., \& Rule, S (1996). A qualitative analysis of parents' and service coordinators' descriptions of variables that influence collaborative relationships. Topics in Early Childhood Special Education, 16(3), 322-347. 
Dulaney, S. K. (2012). A middle school's response-to-intervention journey: Building systematic processes of facilitation, collaboration, and implementation. NASSP Bulletin, 97 (1), 5377. DOI: $10.1177 / 0192636512469289$

Epstein, J. L. (2001). School, family, and community partnerships: Preparing educators and improving schools. Boulder, CO: Westview Press.

Esler, A., Godber, Y., \& Christenson, S. L. (2008). Best practices in supporting school-family partnerships. In A. Thomas, \& J. Grimes (Eds.), Best practices in school psychology V (pp. 917-1120). Washington, DC: National Association of School Psychologists.

Fewster-Thuente, L. (2015). Working together toward a common goal: A grounded theory of nurse-physician collaboration. Research for Practice, 24, 356-362.

Frey, B. B., Lohmeier, J. H., Lee, S. W., \& Tollefson, N. (2006). Measuring collaboration among grant partners. American Journal of Evaluation, 27, 383-392.

Freeman, J., Sugai, G., Simonsen, B., \& Everett, S. (2017) MTSS Coaching: Bridging Knowing to Doing. Theory Into Practice, 56 (1), 29-37. DOI:10.1080/00405841.2016.1241946

Gajda, R. (2004). Utilizing collaboration theory to evaluate strategic alliances. American Journal of Evaluation, 25, 65-77.

Gajda, R., \& Koliba, C. (2007). Evaluating the imperative of inter-personal collaboration: A school improvement perspective. American Journal of Evaluation, 28, 26-44.

Glueck, C.L., \& Reschly, A.L. (2014). Examining congruence within school-family partnerships: Definition, importance, and current measurement approaches. Psychology in the Schools, $51,296-315$.

Graham, J. R., \& Barter, K. (1999). Collaboration: A social work practice method. Families in Society, 80, 6-13. 
Hallam, P. R., Smith, H. R., Hite, J. M., Hite, S. J., \& Wilcox, B. R. (2015). Trust and collaboration in PLC teams: Teacher relationships, principal support, and collaborative benefits. NASSP Bulletin, 99, 193-216.

Henderson, A. T. \& Mapp, K. L. (2002). A new wave of evidence: The impact of school, family, and community connections on student achievement. National Center for Family \& Community Connections with Schools. Retrieved from https://www.sedl.org/connections/resources/evidence.pdf

Hodges, S., Hernandez, M., \& Nesman, T. (2003). A developmental framework for collaboration in child-serving agencies. Journal of Child and Family Studies, 12, 291-205.

Hogue, T. (1993). Community-based collaboration: Community wellness multiplied. Bend, OR: Chandler Center for Community Leadership. Retrieved from http://crs.uvm.edu/nnco/collab/wellness.html

Individuals with Disabilities Education Improvement Act of 2004. 20 U.S.C. 1414(d)(1)(B) (2006).

Kellerman, B. (2004). How bad leadership happens. Leader to Leader, 35, 41-46.

Keyton, J., Ford, D. J., \& Smith, F. I. (2008). A mesolevel communicative model of collaboration. Communication Theory, 18, 376-406.

Lancaster, G., Kolakowsky-Hayner, S., Kovacich, J., \& Greer-Williams, N. (2015). Interdisciplinary communication and collaboration among physicians, nurses, and unlicensed assistive personnel. Journal of Nursing Scholarship, 47, 275-284.

Lewis, L. K. (2006). Collaborative interaction: Review of communication scholarship and a research agenda. In C. S. Beck (Ed.), Communication yearbook 30 (pp. 197-247). Mahwah, NJ: Erlbaum. 
Lucyshyn, J. M., Horner, R. H., Dunlap, G., Albin, R. W., \& Ben, K. R. (2002). Positive behavior support with families. In J. M. Lucyshyn, G. Dunlap, \& R. W. Albin (Eds.), Families and positive behavior support: Addressing problem behavior in family contexts (pp. 3-43). Baltimore, MD: Brookes.

Mattessich, P. W., \& Monsey, B.R. (1992). Collaboration: What makes it work? St. Paul, MN: Amherst H. Wilder Foundation.

Mulvale, G., Embrett, M., \& Razavi, S. D. (2016). "Gearing up” to improve interprofessional collaboration in primary care: A systematic review and conceptual framework. $B M C$ Family Practice, 17(83), 1-13.

National Association of School Psychologists (2012). Position statement: School-family partnering to enhance learning. Retrieved from http://www.nasponline.org/about_nasp/positionpapers/Home-SchoolCollaboration.pdf

Nijhuis, B. J. G., Reinders-Messelink, H. A., de Blecourt, A. C. E., Olijve, W. G., Groothoff, J. W., Nakken, H., . . Postuma, K. (2007). A review of salient elements defining team collaboration in paediatric rehabilitation. Clinical Rehabilitation, 21(3), 195-211. doi:10.1177/0269215506070674

Olivos, E. M., Gallagher, R. J., \& Aguilar, J. (2010). Fostering collaboration with culturally and linguistically diverse families of children with moderate to severe disabilities. Journal of Education \& Psychological Consultation, 20, 28-40.

Olson, L. M. (2003). Pathways to collaboration. Reclaiming Children and Youth, 11, 236-239.

Patten, M.L. (2014). Questionnaire research: A practical guide ( $4^{\text {th }}$ edition). Glendale, CA. Pyrczak Publishing. 
Pianta, R. C., Kraft-Sayre, M., Rimm-Kaufman, S., Gercke, N., \& Higgins, T. (2001).

Collaboration in building partnerships between families and schools: The National Center for Early Development and Learning's Kindergarten Transition Intervention. Early Childhood Research Quarterly, 16, 117-132.

Peterson, N. L. (1991). Interagency collaboration under Part H: The key to comprehensive, multidisciplinary, coordinated infant/toddler intervention services. Journal of Early Intervention, 15, 89-105.

Pullon, S. (2008). Competence, respect, and trust: Key features of successful interprofessional nurse-doctor relationships. Journal of Interprofessional Care, 22, 133-147.

Rowley, W. (2000). Expanding collaborative partnerships among school counselors and school psychologists. Professional School Counseling, 3(3), 224.

Sanetti, L., \& Collier-Meek, M. (2019). Increasing implementation science literacy to address the research-to-practice gap in school psychology. Journal of School Psychology, 76, 33-47. doi:10.1016/j.jsp.2019.07.008

Serpell, Z. N., \& Mashburn, A. J. (2011). Family-school connectedness and children's early social development. Social Development, 21, 21-46.

Skalski, A. K., Minke, K., Rossen, E., Cowan, K. C., Kelly, J., Armistead, R., \& Smith, A. (2015). NASP Practice Model Implementation Guide. Bethesda, MD: National Association of School Psychologists.

Summers, J. A., Hoffman, L., Marquis, J., Turnbull, A., Poston, D., \& Nelson, L. L. (2005). Measuring the quality of family-professional partnerships in special education services. Exceptional Children, 72, 65-81. 
Tschannen-Moran, M. (2001). Collaboration and the need for trust. Journal of Educational Administration, 39, 308-331.

Tschannen-Moran, M. \& Gareis, C. R. (2015). Faculty trust in the principal: An essential ingredient in high-performing schools, Journal of Educational Administration, 53, 66-92.

Tucker, V., \& Schwartz, I. (2013). Parents’ perspectives of collaboration with school professionals: Barriers and facilitators to successful partnerships in planning for students with ASD. School Mental Health, 5, 3-14.

Vangen, S., \& Huxham, C. (2003). Nurturing collaborative relations: Building trust in interorganizational collaboration. Journal of Applied Behavioral Science, 39, 5-31.

Verdon, S., Wong, S., \& McLeod, S. (2016). Shared knowledge and mutual respect: Enhancing culturally competent practice through collaboration with families and communities. Child Language Teaching and Therapy, 32, 205-221.

Williamson, H. J., Young, B.R., Murray, N., Burton, D. L., Levin, B. L., Massey, O. T., \& Baldwin, J. A. (2016). Community-university partnership for research and practice: Application of an interactive and contextual model of collaboration. Journal of Higher Education Outreach Engagement, 20(2), 55-84.

Wood, D. J., \& Gray, B. (1991). Toward a comprehensive theory of collaboration. Journal of Applied Behavioral Science, 27, 139-162.

Woodland, R. H., \& Hutton, M. S. (2012). Evaluating organizational collaborations: Suggested entry points and strategies. American Journal of Evaluation, 33(3), 366-383. 
Table 1

Overview of Studies Selected for Review

\begin{tabular}{|c|c|c|c|c|}
\hline Author & Setting/Subjects & Method & Objective & Results \\
\hline $\begin{array}{l}\text { Abramson \& } \\
\text { Mizrahi, } 1996\end{array}$ & $\begin{array}{l}\text { Healthcare: } 53 \text { social } \\
\text { workers and } 50 \\
\text { physicians }\end{array}$ & Quantitative & $\begin{array}{l}\text { Understand the factors that } \\
\text { contribute to positive and negative } \\
\text { collaboration in the healthcare } \\
\text { setting }\end{array}$ & $\begin{array}{l}\text { Physicians give lower priority to collaboration than do } \\
\text { social workers; communication, respect, and similar } \\
\text { perceptions were top-rated aspects of collaboration by } \\
\text { both professions }\end{array}$ \\
\hline $\begin{array}{l}\text { Adams \& } \\
\text { Christenson, } 2000\end{array}$ & $\begin{array}{l}\text { Education: } 1,234 \\
\text { parents and } 209 \text { teachers }\end{array}$ & Quantitative & $\begin{array}{l}\text { Understand the role of trust in } \\
\text { building and maintaining family- } \\
\text { school relationships }\end{array}$ & $\begin{array}{l}\text { Improving home-school communication is a primary } \\
\text { way to enhance trust; quality of interaction is a better } \\
\text { predictor of trust than is quantity of interactions }\end{array}$ \\
\hline Amabile et al., 2001 & $\begin{array}{l}\text { Education: } 14 \\
\text { participants }\end{array}$ & Qualitative & $\begin{array}{l}\text { Determine collaborative team } \\
\text { characteristics, environmental } \\
\text { characteristics, and processes that } \\
\text { lead to effective collaboration }\end{array}$ & $\begin{array}{l}\text { Characteristics of successful collaboration include } \\
\text { leadership skill, institutional support, and effective use } \\
\text { of member capabilities }\end{array}$ \\
\hline $\begin{array}{l}\text { Bailey \& Koney, } \\
2000\end{array}$ & $\begin{array}{l}\text { Healthcare and human } \\
\text { services }\end{array}$ & Theoretical & $\begin{array}{l}\text { Provide theoretical and practical } \\
\text { information to help organizations } \\
\text { form strategic alliances }\end{array}$ & $\begin{array}{l}\text { Levels of collaboration from cooperation to } \\
\text { coordination to collaboration to coadunation; includes } \\
\text { shared practices and shared decision making }\end{array}$ \\
\hline $\begin{array}{l}\text { Beverly \& Thomas, } \\
1999\end{array}$ & Education & Theoretical & $\begin{array}{l}\text { Review the characteristics that } \\
\text { lead to productive collaboration } \\
\text { between families and schools in } \\
\text { early intervention }\end{array}$ & $\begin{array}{l}\text { Effective collaboration includes establishment of } \\
\text { roles, role clarification and change, administrative } \\
\text { support, training, acknowledgement of diversity, and } \\
\text { respect }\end{array}$ \\
\hline $\begin{array}{l}\text { Blue-Banning, } \\
\text { Summers, } \\
\text { Frankland, Nelson, } \\
\& \text { Beegle., } 2004\end{array}$ & $\begin{array}{l}\text { Education: } 33 \text { focus } \\
\text { groups }\end{array}$ & Qualitative & $\begin{array}{l}\text { Determine the empirical } \\
\text { components of interpersonal } \\
\text { partnership and collaboration }\end{array}$ & $\begin{array}{l}\text { Indicators of effective collaboration include } \\
\text { communication, commitment, equality, skills, trust, } \\
\text { and respect }\end{array}$ \\
\hline
\end{tabular}


Bronstein, $2003 \quad$ Healthcare

Theoretical

Develop interdisciplinary model of collaboration within social work

Theoretical

Define collaboration and describe the factors that influence homeschool collaboration and 226 coordinators

Rule, 1996

Epstein, 2001

Education

Fewster-Thuente, 2015

Frey, Lohmeier, Lee, \&Tollefson, 2006

Gajda, 2004
Education
Healthcare: 22 nurses

Education

Theoretical

Qualitative

Theoretical
Qualitative

Theoretical

Determine the variables that enhance or detract from collaboration between parents and professionals in early intervention

Define the types of involvement in school, family, and community partnership

Theorize collaboration as a basic

Develop a scale to determine level of collaboration between stakeholders

Describe the role of program evaluation in collaboration and strategic alliances social process
Development of a two-part model that

includes components (interdependence, newly created professional activities, flexibility, collective

ownership of goals, and reflection on process) and influences (professional role, structural characteristics, personal characteristics, and history)

Educational legislation, home- and family-related factors, school-related factors, community-related factors, and underlying roles and assumptions all influence home-school collaboration

Interpersonal and communication skills are essential for effective collaboration between services, coordinators, and parents

Six types of involvement: (1) parenting, (2) communicating, (3) volunteering, (4) learning at home, (5) decision making, and (6) collaborating with the community

Collaboration is a social process in which a group is formed and harmony is attained through achievement of a common goal.

Five levels of collaboration: (1) networking, (2) cooperation, (3) coordination, (4) coalition, and (5) collaboration

Collaboration is imperative; collaboration is known by many names; collaboration is a journey, not a destination; the personal is as important as the procedural; and collaboration develops in stages 


$\begin{array}{ll}\text { Gajda \& Koliba, } \quad \text { Education } & \text { Theoretical } \\ 2007 & \begin{array}{l}\text { Describe and assess interpersonal } \\ \text { collaboration through the } \\ \text { illustration of a multistage } \\ \text { collaboration evaluation process }\end{array}\end{array}$

Graham \& Barter, Healthcare
1999

Hallam et al., 2015 Education: 12 teams

Qualitative

Hodges et al., 2003

Community: 9 sites

Qualitative

Hogue, 1993

Community

Keyton, Ford, \&

Smith, 2008

Lancaster et al.

2015
General collaboration

Healthcare: 30

providers
Theoretical

Define the levels of collaboration and the associated constructs

Define a communicative model of collaboration at the team level

Qualitative

(1)

Determine the role of
Theoretical
Determine the developmental framework of collaboration

attributes, and phases of

collaboration

Determine the role of trust in collaboration

interdisciplinary care in the healthcare setting
Key traits of interpersonal collaboration include shared purpose, cycle of inquiry, dialogue, decision making, action, and evaluation

Four phases of collaboration: (1) problem setting, (2) direction setting, (3) implementation, and (4) structuring and evaluation

Trust is reached when participants fulfill their assignments and responsibilities and when they show mutual kindness and patience. Trust facilitates collaboration by enabling teachers to be open with sensitive information that might cause vulnerability

Collaboration is a developmental

process that involves five stages: (1) individual action,

(2) one-on-one interaction, (3) new service development, (4) professional collaboration, and (5) true collaboration

Five levels of collaboration: (1) networking (communication), (2) cooperation, (3) coordination,

(4) coalition, and (5) collaboration. Collaboration includes shared decision making, defined roles, combined resources, trust, leadership, shared ideas and decisions, and open communication

The bulk of collaborative communication occurs at the team level and requires strong relationships between individuals and organizations

Coordination of various treatments and interventions is critical to prevent errors and fragmentation of care 


$\begin{array}{llll}\begin{array}{l}\text { Mattessich \& } \\ \text { Monsey, 1992 }\end{array} & \begin{array}{l}\text { Healthcare and } \\ \text { education }\end{array} & \text { Theoretical } & \begin{array}{l}\text { Review the key constructs related } \\ \text { to effective collaboration }\end{array} \\ \begin{array}{l}\text { Mulvale, Embrett, \& } \\ \text { Razavi, 2016 }\end{array} & \text { Healthcare } & \begin{array}{l}\text { Systematic } \\ \text { review }\end{array} & \begin{array}{l}\text { Define the factors that improve } \\ \text { collaboration in primary care }\end{array}\end{array}$

\section{National \\ Association of \\ School}

Education

Psychologists, 2012

Nijhuis et al., $2007 \quad$ Healthcare

Olivos, Gallagher,

\& Aguilar, 2010

Education

Healthcare

Pianta, Kraft-Sayre, Education

Rimm-Kaufman,

Gercke, \& Higgins,

2001 $\begin{array}{ll}\text { Systematic } & \text { Define the factors that improve } \\ \text { review } & \text { collaboration in primary care }\end{array}$

Theoretical Review factors of family-school partnerships that enhance the learning of children

Systematic

Review

Theoretical

Review the salient elements of collaboration in pediatric rehabilitation

Define the elements that enhance family-school collaboration with culturally and linguistically diverse families

Theoretical

Provide a model for building respectful and productive collaboration

Qualitative

Describe collaboration among university researchers, preschool teachers, elementary school staff, and parents
Characteristics of collaboration can be grouped into environmental factors, membership characteristics, process structure, purpose, and resources

Collaboration can be broken into five main factors: (1) team structure, (2) social processes, (3) formal processes, (4) team attitudes, and (5) individual factors

Family-school partnership involves open communication, mutually agreed-upon goals, joint decision making, shared responsibility, and mutual respect

Essential elements in team collaboration include communication, decision making, organization, shared goal setting, team process, and parent involvement

When working with culturally and linguistically diverse families, it is essential to provide them with full access to the school, share power equally, provide all options and shared decision making, and establish point persons to ensure open communication

Collaboration involves distinct milestones:

(1) getting together, (2) building trust and ownership,

(3) developing a strategic plan, (4) identifying a shared mission and vision, (5) providing administrative support, and (6) ensuring mutually beneficial outcomes

Essential elements in collaboration include a shared mission, communication, and mutual respect 


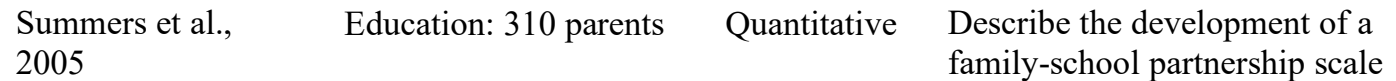

Tschannen-Moran, Education

2001

Tucker \& Schwartz, Education: 135 parents 2013

Vangen \& Huxham, General collaboration 2003

Verdon et al., 2016

Williamson et al. 2016

Woodland \& Hutton, 2012
General collaboration
Community and education: 14 international sites

\section{Qualitative}

$$
\begin{aligned}
& \text { membership of parents in the IEP } \\
& \text { process }
\end{aligned}
$$

Determine the barriers to full

Theoretical

Discuss the significance of trust in collaborative partnerships

Qualitative

Describe collaboration between speech and language therapists and families and support children from culturally and linguistically diverse backgrounds

Community-university: 5 community partners, 6 academic mentors, 13

scholars
Theoretical
Qualitative

Discuss the utility of applying the contextual and interactive model of community-university collaboration to a translational research education program

Describe the Collaboration Evaluation and Improvement Framework and suggestions for evaluating collaborative relationships
Two dimensions of family-professional partnerships: (1) child-focused relationships and (2) family-focused relationships

Trust is an essential component in nurturing collaborative relationships

Common barriers include a lack of opportunities to provide input, communication difficulties, and negative perceptions of school professionals

Trust building is problematic, and management of trust implies the abilities to cope in situations where trust is lacking and build trust when possible

Collaboration with communities can

facilitate understanding of children's cultural context and build respect

Community-university collaboration depends on trust and mutual respect, adequate communication,

development of an action agenda, respect for diversity, and respect for culture of the setting

Partnerships form around a shared purpose; they are a nested and networked phenomenon with predictable stages of development 
Table 2

Summary of the Constructs

\begin{tabular}{|c|c|c|}
\hline Construct & Key Points & References \\
\hline $\begin{array}{l}\text { Open } \\
\text { Communication }\end{array}$ & $\begin{array}{l}\text { Open communication includes } \\
\text { any form of honest and clear } \\
\text { communication between two or } \\
\text { more parties; includes similar } \\
\text { constructs, such as conflict } \\
\text { management and other forms of } \\
\text { effective communication. }\end{array}$ & $\begin{array}{l}\text { Abramson \& Mizrahi, 1996; Adams \& } \\
\text { Christenson, 2000; Amabile et al., 2001; } \\
\text { Blue-Banning et al., 2004; Boyer \& } \\
\text { Thompson, 2014; Bronstein, 2003; } \\
\text { Dinnebeil et al., 1996; Epstein, 2001; } \\
\text { Fewster-Thuente, 2015; Frey et al., } \\
\text { 2006; Gajda, 2004; Graham \& Barter, } \\
\text { 1999; Hallam et al., 2015; Hogue, 1993; } \\
\text { Lancaster et al., 2015; Mulvale et al., } \\
\text { 2016; National Association of School } \\
\text { Psychologists, 2012; Nijhuis et al., 2007; } \\
\text { Olivos et al., 2010; Pianta et al., 2001; } \\
\text { Summers et al., 2005; Tucker \& } \\
\text { Schwartz, 2013; Williamson et al., } 2016\end{array}$ \\
\hline Trust & $\begin{array}{l}\text { Trust is directly related to } \\
\text { communication; trust is } \\
\text { developed when there are time, } \\
\text { effort, and energy put into the } \\
\text { development of a functioning } \\
\text { system of communication. }\end{array}$ & $\begin{array}{l}\text { Adams \& Christenson, 2000; Amabile et } \\
\text { al., 2001; Blue-Banning et al., 2004; } \\
\text { Bronstein, 2003; Cowan et al., 2004; } \\
\text { Dinnebeil et al., 1996; Frey et al., 2006; } \\
\text { Graham \& Barter, 1999; Hallam et al., } \\
\text { 2015; Hodges et al., 2003; Lucyshyn } \\
\text { Horner, Dunlap, Albin, \& Ben, 2002; } \\
\text { Olson, 2003; Summers et al., 2005; } \\
\text { Tschannen-Moran, 2001; Tucker \& } \\
\text { Schwartz, 2013; Vangen \& Huxham, } \\
\text { 2003; Williamson et al., } 2016\end{array}$ \\
\hline Mutual Respect & $\begin{array}{l}\text { Mutual respect includes respect } \\
\text { for the ideas, skills, and } \\
\text { knowledge of others; includes } \\
\text { respect for individual } \\
\text { differences, conflict resolution, } \\
\text { cultural competence, and } \\
\text { differences in perceived power. }\end{array}$ & $\begin{array}{l}\text { Abramson \& Mizrahi, 1996; Amabile et } \\
\text { al., 2001; Beverly \& Thomas, 1999; } \\
\text { Blue-Banning et al., 2004; Bronstein, } \\
\text { 2003; Cowan et al., 2004; Dinnebeil et } \\
\text { al., 1996; Hallam et al., 2015; Lancaster } \\
\text { et al., 2015; Lewis, 2006; Lucyshyn et } \\
\text { al., 2002; National Association of } \\
\text { School Psychologists, 2012; Pianta et } \\
\text { al., 2001; Summers et al., 2005; Tucker } \\
\text { \& Schwartz, 2013; Verdon et al., 2016; } \\
\text { Williamson et al., 2016 }\end{array}$ \\
\hline Shared Goals & $\begin{array}{l}\text { Shared goals include goals that } \\
\text { are mutually determined by the }\end{array}$ & $\begin{array}{l}\text { Beverly \& Thomas, 1999; Boyer \& } \\
\text { Thompson, 2014; Bronstein, 2003; } \\
\text { Cowan et al., 2004; Fewster-Thuente, }\end{array}$ \\
\hline
\end{tabular}


team to achieve mutually agreed-upon outcomes.

Common

Understanding

Shared

Responsibility

Active

Participation

Shared Decision Making
Common understanding is the idea that, despite differences in ideas, skills, and knowledge, team members hold similar overall perceptions and shared visions.

Shared responsibility includes the effective use of member capabilities, establishment of roles, equal contribution, and effective use of individual strengths.

Active participation includes equal contribution as each team member embraces his or her specific role; includes cooperation, shared problem solving, and active engagement in the process.

Shared decision making means that each team member has had the opportunity to provide his or her input, and there is consensus in the decision making process.
2015; Gajda, 2004; Hogue, 1993; Lucyshyn et al., 2002; Mulvale et al., 2016; National Association of School Psychologists, 2012; Nijhuis et al., 2007; Olson, 2003; Pianta et al., 2001; Summers et al., 2005; Verdon et al., 2016; Woodland \& Hutton, 2012

Abramson \& Mizrahi, 1996; Amabile et al., 2001; Beverly \& Thomas, 1999; Gajda, 2004; Graham \& Barter, 1999; Hodges et al., 2003; Nijhuis et al., 2007; Olson, 2003; Verdon et al., 2016

Adams \& Christenson, 2000; Amabile et al., 2001; Beverly \& Thomas, 1999; Bronstein, 2003; Cowan et al., 2004; Dinnebeil et al., 1996; Fewster-Thuente, 2015; Gajda, 2004; Graham \& Barter, 1999; Hallam et al., 2015; Hodges et al., 2003; Hogue, 1993; Lancaster et al., 2015; Lewis, 2006; Lucyshyn et al., 2002; Mattessich \& Monsey, 1992;

National Association of School

Psychologists, 2012; Olivos et al., 2010; Olson, 2003; Tucker \& Schwartz, 2013

Adams \& Christenson, 2000; Boyer \& Thompson, 2014; Cowan et al., 2004; Fewster-Thuente, 2015; Graham \& Barter, 1999; Hallam et al., 2015; Hodges et al., 2003; Hogue, 1993; Lucyshyn et al., 2002; Mattessich \& Monsey, 1992; Nijhuis et al., 2007;

Olson, 2003; Tucker \& Schwartz, 2013; Verdon et al., 2016

Bailey \& Koney, 2000; Blue-Banning et al., 2004; Bronstein, 2003; Cowan et al., 2004; Epstein, 2001; Frey et al., 2006;

Gajda, 2004; Graham \& Barter, 1999;

Hodges et al., 2003; Hogue, 1993;

Mulvale et al., 2016; National

Association of School Psychologists, 2012; Nijhuis et al., 2007; Olivos et al., 2010; Summers et al., 2005 
Table 3

Common Constructs among Empirical Definitions of Collaboration

\begin{tabular}{|c|c|c|c|c|c|c|c|c|c|c|c|c|c|c|c|c|}
\hline \multirow[b]{2}{*}{ Construct } & \multicolumn{16}{|c|}{ Empirical Definition } \\
\hline & 1 & 2 & 3 & 4 & 5 & 6 & 7 & 8 & 9 & 10 & 11 & 12 & 13 & 14 & 15 & 16 \\
\hline Open Communication & - & $\bullet$ & $\bullet$ & $\bullet$ & $\bullet$ & • & & $\bullet$ & • & $\bullet$ & $\bullet$ & • & • & $\bullet$ & - & $\mathrm{x}$ \\
\hline Trust & $\bullet$ & & $\mathrm{x}$ & - & $\mathrm{x}$ & $\mathrm{x}$ & & - & & - & - & - & - & & - & • \\
\hline Mutual Respect & • & & $\mathrm{x}$ & & $\mathrm{x}$ & $\mathrm{x}$ & $\mathrm{x}$ & • & • & & - & - & $\mathrm{x}$ & • & • & \\
\hline Shared Goals & & $\bullet$ & & $\mathrm{x}$ & & & $\bullet$ & & & $\bullet$ & & & $\bullet$ & $\bullet$ & $\mathrm{x}$ & $\mathrm{x}$ \\
\hline Common Understanding & $\bullet$ & & & • & & & & & • & & $\mathrm{x}$ & $\mathrm{x}$ & $\mathrm{x}$ & $\mathrm{x}$ & $\mathrm{x}$ & \\
\hline Shared Responsibility & $\mathrm{x}$ & $\mathrm{x}$ & $\mathrm{x}$ & $\bullet$ & $\mathrm{x}$ & $\mathrm{x}$ & & & & • & $\mathrm{x}$ & • & $\bullet$ & & & \\
\hline Active Participation & & $\mathrm{x}$ & $\mathrm{x}$ & $\bullet$ & & $\mathrm{x}$ & $\bullet$ & & & $\bullet$ & & & $\mathrm{x}$ & & & $\mathrm{x}$ \\
\hline Shared Decision Making & & & & $\bullet$ & & & & & & & $\bullet$ & & • & & & $\mathrm{x}$ \\
\hline Implementation & & & & & & & & & & & & & & & & \\
\hline
\end{tabular}

Note. $1=$ Amabile et al., 2001; $2=$ Fewster-Thuente, 2015; $3=$ Hallam et al., 2015; $4=$ Hodges, Hernandez, \& Nesman, 2003; $5=$ Lancaster et al., 2015; $6=$ Tucker \& Schwartz, 2013; $7=$ Verdon, Wong, and McLeod, 2016; 8 = Williamson et al., 2016; 9 = Abramson \& Mizrahi, 1996; $10=$ Adams \& Christenson, 2000; 11 = Blue-Banning, et al., 2004; 12= Dinnebeil, Hale, \& Rule, 1996; 13 = Nijhuis, et. al., 2007; 14 = PIanta, et al., 2001; $15=$ Summer, et al., 2005; 16 = Tschannen-Moran, 2001

- = element is present; $\mathrm{x}=$ element is assumed 
Table 4

Common Constructs among Theoretical Definitions of Collaboration

Theoretical Definition

\begin{tabular}{|c|c|c|c|c|c|c|c|c|c|c|c|c|c|c|c|c|c|c|}
\hline Construct & 1 & 2 & 3 & 4 & 5 & 6 & 7 & 8 & 9 & 10 & 11 & 12 & 13 & 14 & 15 & 16 & 17 & 18 \\
\hline Open Communication & $\mathrm{x}$ & & - & $\bullet$ & $\mathrm{x}$ & $\bullet$ & & & • & $\bullet$ & & • & $\bullet$ & & • & & - & • \\
\hline Mutual Respect & $\mathrm{x}$ & & - & & $\mathrm{x}$ & $\mathrm{x}$ & & $\bullet$ & & & & & • & & • & & & \\
\hline Common Understanding & & & & $\bullet$ & $\bullet$ & $\mathrm{x}$ & & $\mathrm{x}$ & & & & & & & $\bullet$ & $\mathrm{x}$ & & \\
\hline Shared Responsibility & $\mathrm{x}$ & $\bullet$ & $\bullet$ & $\bullet$ & $\bullet$ & $\mathrm{x}$ & $\mathrm{x}$ & $\bullet$ & & $\mathrm{x}$ & & $\mathrm{x}$ & $\bullet$ & $\mathrm{x}$ & $\bullet$ & & & \\
\hline Implementation & & & & & & & & & & & - & & & & & & & $\mathrm{x}$ \\
\hline
\end{tabular}

Note. 1 = Bronstein, 2003; 2 = Bailey \& Koney, 2000; 3 = Cowan, Swearer Napolitano, \& Sheridan, 2004; 4 = Gajda, 2004; $5=$ Graham \& Barter, $1999 ; 6=$ Mulvalve, Embrett, \& Razavi, 2016; $7=$ Olson, 2003; 8= Beverly \& Thomas, 1999; 9 = Esptein, 2001; $10=$ Frey, et al, 2006; $11=$ Gajda \& Koliba, 2007; 12 = Hogue, 1993; 13= Keyton, Ford, Smith, 2008; 14 = Mattessich \& Monsey, 1992; $15=$ NASP, 2012; 16= Olivos, Gallagher, \& Aguilar, 2010; 17 = Vangen \& Huxham, 2003; 18 = Woodland \& Hutton, 2012

$\bullet=$ element is present; $\mathrm{x}=$ element is assumed 